\title{
A Possible Use of Selected Essential Oils and Citrosept to Inhibit the Growth of Fusarium solani Mart. (Sacc.)
}

\author{
Teresa Krzyśko-Łupicka1, Sanaa Mahdi Oraibi², Ewelina Kurp¹, Weronika Walkowiak \\ ${ }^{1}$ Department of Biotechnology and Molecular Biology, University of Opole, Opole, Poland \\ ${ }^{2}$ Department of Chemistry, Microbiology and Biotechnology of Environment, West Pomeranian University of Technology in Szczecin, \\ Szczecin, Poland \\ Email: teresak@uni.opole.pl
}

How to cite this paper: Krzyśko-Łupicka, T., Mahdi Oraibi, S., Kurp, E. and Walkowiak, W. (2016) A Possible Use of Selected Essential Oils and Citrosept to Inhibit the Growth of Fusarium solani Mart. (Sacc.). Advances in Microbiology, 6, 1159-1165.

http://dx.doi.org/10.4236/aim.2016.614104

Received: November 17, 2016

Accepted: December 26, 2016

Published: December 29, 2016

Copyright $\odot 2016$ by authors and Scientific Research Publishing Inc. This work is licensed under the Creative Commons Attribution International License (CC BY 4.0).

http://creativecommons.org/licenses/by/4.0/

\section{(c) (i) Open Access}

\begin{abstract}
Laboratory experiments have been carried out to determine the effects of lemon, cedar, pine and thyme oils as well as Citrocept on the growth of Fusarium solani Mart. (Sacc.) mycelium isolated from stored potato tubers. The biotic property of essential oils and Citrocept in inhibiting the linear growth of $F$. solani was assessed with the use of poisoned culture media, whereas the fungistatic property was determined by calculating, with the use of Abbott formula, the percentage indicating how many fungal colonies were inhibited from growth. A complete inhibition of the pathogen's growth was observed in the presence of thyme oil at a concentration of $0.2 \%$ to $2 \%$ as well as in the presence of lemon oil at a concentration of 5\% and 15\%. Citrosept only at high concentrations caused a slower growth of $F$. solani. No fungistatic effects of cedar and pine oils were observed.
\end{abstract}

\section{Keywords}

Fusarium solani, Essential Oils, Fungistatic Effects

\section{Introduction}

The fungi of Fusarium spp. genus causes crop loss by affecting many species of edible plants both during the vegetation and storage periods. Additionally, since they produce mycotoxins harmful to humans, animals and plants, the quality of the crop decreases as well.

A particular problem is the deterioration of the quality of the basic raw material for industrial and consumer potato tubers which are infested with dry rot. Among the fac- 
tors increasing the risk of potato tubers being infected are inappropriate storage conditions and the way of potato cultivation. Cwalina-Ambroziak and Wróbel (2005) [1] proved that using nitrogenous fertilisers both improves the potato crop and also increases susceptibility to infection Fusarium. The perpetrators of this universal disease of potatoes are for example Fusarium solani var. coeruleum and F. sulphureum [2] [3] [4].

The disease occurs mainly in the autumn but, in fact, potato tubers are infected as early as in the spring. In the case of stored potatoes, the infection usually reveals itself mid-December.

On the surface of infected bulbs appear initially slightly recessed spots, and in their place are formed quite extensive tissue defects, skin wrinkles and collapses in the form of concentrically arranged rings and folds. On the surface formed white, yellow or pink panels raid. Infected potatoes lose significant amounts of water thereby transform into a lump or pulverulent material is cured [5].

Optimal storage conditions ensure the smallest loss and high quality of potato tubers. However, only the most modern storages, where climate control systems are installed, are certain to preserve high quality of potato tubers [6]. At present, however, more than a half of the collected potato crop is kept in traditional, underground storages, where a fungicide (Fungazil 100 SL-the only one currently registered in Poland) is used as a means of protecting the potatoes against storage diseases.

In spite of storages becoming more and more advanced (regulated temperature, pressure and constant ventilation); the issue of the unwanted microflora still persists. One of the ideas aiming at limiting the loss caused by fungal growth is to use essential oils as an environment-friendly method of protecting potato tubers against the dry rot. Many essential oils (of citrus fruits, forest plants, tee tree, basil, geranium) show fungicidal properties, i.e. they either prevent or inhibit the development of Fusarium's [7]-[12] mycelium, the final effect being achieved as a result of volatile compounds present in the essential oils [13] and microorganisms' susceptibility to them. For this reason, the reports on biological activity of the oils are sometimes inconclusive. Given the diversity of phytopathogens and their varying degrees of susceptibility, it is very difficult to choose the right oil at just the right concentration.

The aim of the study was to evaluate in a laboratory the effects of selected essential oils on the growth of Fusarium solani (Mart) Sacc., species isolated from infected potato tubers in the early spring.

\section{Material and Methods}

The subject of the analysis was a species of fungus, i.e. Fusarium solani (Mart) Sacc., isolated from infected potato tubers in the early spring. Round, $10-\mathrm{mm}$ plates containing the culture medium were used as the inoculum in the study. The plates were grown over with mycelium. This inoculum was obtained by means of the slide culture technique. The culture medium was injected with $1 \mathrm{~cm}^{3}$ of standardised suspension of fungi with a density of $2 \times 10^{6} \mathrm{CFU} / \mathrm{cm}^{3}$ and incubated for 10 days at a temperature of $25^{\circ} \mathrm{C}$. 
The essential oils analysed were as follows: lemon oil produced by ETJA; cedar, pine and thyme oils by BAMER; and grapefruit seed extract (Citrosept) by Cintarmani.

The evaluation of fungicidal activity of essential oils and Citrosept to a strain of $F$. solani were made by incubation of the substrate Czapek. The essential oils were added to the liquefied Czapek-Dox culture medium in amounts allowing one to obtain the following concentration levels: $0.2,0.5,1.0,2.0,5.0,10.0,15.0$. At solidified medium was placed rings overgrown mycelium $F$. solani. The control was the culture of the analysed strains growing on Czpek-Dox medium but without the essential oils. The incubation was carried out at a temperature of $25^{\circ} \mathrm{C}$ for 10 days.

The biotic activity of essential oils in reducing the linear growth of the fungus Fusarium solani (Mart) Sacc. assessed by medium poisoned method [14]:

- The fungus grew on the PDA growth medium for 14 days at a temperature of $25^{\circ} \mathrm{C}$.

- Round, 10-mm plates containing the culture medium were used as the inoculum in the study.

- The control sample was the culture of the analysed strains growing on the PDA growth medium but without the essential oils.

- The linear growth index of mycelium (T) and the fungistatic properties of the oils were assessed on the basis of measurements of the growth of fungal colonies.

The growth rate index of Fusarium solani was calculated in accordance with the following formula:

$$
T=\frac{A}{D}+\frac{b 1}{d 1}+\cdots+\frac{b x}{d x}
$$

\section{T-index of linear growth. \\ $A$-average measured value of the diameter of colonies $[\mathrm{mm}]$. \\ $D$-duration of the experiment. \\ $b 1 \cdots b x$-increase in colonies diameter $[\mathrm{mm}]$. \\ $d 1 \cdots d x$ - number of days since the last measurement.}

The fungistatic activity of the analysed oils was determined by calculating, with the use of Abbott formula, the percentage indicating how many fungal colonies were inhibited from growth:

$$
I=\frac{C-M}{C} \times 100
$$

\section{I-fungus linear growth inhibition index [\%].}

C-fungus colony diameter on the control plate $[\mathrm{mm}]$.

$M$-fungus colony diameter on the control plate containing a given oil (the analysed substance) in the agar $[\mathrm{mm}]$.

Paralelly, the influence of the oils on morphological features of F. solani was examined.

All analyses were done in three repetitions. A two-way analysis of variance (ANOVA) was used to examine the effect of essential oils. A post-hoc test by Tukey HSD was used to determine significant differences at a level of $\mathrm{P}<0.05$. All statistics were done using Statistica 10.0 (StatSoft). 


\section{Results and Discussion}

Degree of spawn F. solani was varied and depend on the nature and the concentration of the test oils. The effectiveness of their actions determined by qualitative and quantitative composition of the active substance contained in the essential oil (Table 1).

Thyme oil caused a complete inhibition of mycelium development regardless of the concentration (Table 2). Lemon oil was only effective at concentrations 5\% and $15 \%$ (Figure 1). It was thus assumed that the examined F. solani strain was highly susceptible to thymol and carvacrol, which are the main components of thyme oil [15] [16]. Klimach et al. (1996) [19] demonstrated the same effects of this oil, albeit on other culprit of potato tubers dry rot, i.e. F. sulphureum.

The analysed strain proved to be less susceptible to biologically active components of lemon oil such as citral whose activity in this oil was further strengthened by isomers of geraniol and $\gamma$-terpinen [15] [20] [21].

As for Citrocept, it showed fungistatic effects only if at high concentration, i.e. 20\%, $25 \%$ and $30 \%$. The mycelium growth rate index in the presence of pine oil as well as cedar oil, regardless of the concentration, was on the average $23 \%$ smaller than in the control sample (Figure 1). The above indicated that the susceptibility of the analysed species to biologically active substances contained in those oils (pinene, limonene, cedrene, himachalene) was low [21] [22].

Table 1. The active substances in the analysed essential oils and Citrosept.

\begin{tabular}{cc}
\hline $\begin{array}{c}\text { Oils and } \\
\text { estracts }\end{array}$ & Biological activity substances [\%] \\
\hline Lemon & D-limonen $(61.8-68.5), \gamma$-terpinen $(7.2-10.6), \beta$-pinen $(8.1-12.2), \alpha$-cytral $(4-5)$, \\
{$[12][15]$} & sabinen $(0.03-1.6), \alpha$-pinen, geranial, geraniol, $\beta$-kariofyllen, neral, linalool, p-cymen \\
Thyme & thymol $(18-80), \gamma$-terpinen $(8.8), p$-cymen $(7.8-36.5)$, karwakrol $(1-21)$, \\
{$[16]$} & 1,8 -cyneol $(0-19)$ \\
Pine $[17]$ & linalool $(24-47), \alpha$-pinen $(10.2-51), \beta$-pinen $(1-18), \mathrm{p}$-cymen $(0.1-0.2)$ \\
{$[18]$} & limonen $(0-34), \alpha$-terpineol $(0.8-0.2), \Delta$-karen-3 $(1-61)$ \\
Cedare & $\alpha$-cedren $(21.1-35), \beta$-cedren $(7.7-8.2)$, cedrol $(4-22.2), \beta$-himachalen $(2.1-41.9)$, \\
{$[13]$} & $\alpha$-himachalen $(0-15.7), \gamma$-himachalen $(0-9.7)$ \\
Citrosept & Bioflavonoids $(19.7 \%)$ and glycosides in the form of: naringiny and proteins \\
{$[10][11]$} &
\end{tabular}

Table 2. The influence of selected concentrations of essential oils on the growth rate index (T) of mycelium of Fusarium solani Mart. (Sacc.)

\begin{tabular}{|c|c|c|c|c|c|}
\hline \multicolumn{6}{|c|}{ oils } \\
\hline $\begin{array}{c}\text { Concentration } \\
(\%)\end{array}$ & Control & cedar & pine & thyme & lemon \\
\hline 0.2 & \multirow{4}{*}{$53.18 \mathrm{a}$} & $31.68 \mathrm{~d}$ & $33.74 \mathrm{c}$ & 0 & $36.09 \mathrm{~b}$ \\
\hline 0.5 & & $27.27 \mathrm{f}$ & $30.48 \mathrm{~d}$ & 0 & $8.46 \mathrm{~h}$ \\
\hline 1.0 & & $30.70 \mathrm{~d}$ & $28.92 \mathrm{e}$ & 0 & 0 \\
\hline 2.0 & & $28.41 \mathrm{e}$ & $26.00 \mathrm{~g}$ & 0 & 0 \\
\hline
\end{tabular}

Values denoted with the same letters $(\mathrm{a}, \mathrm{b}, \cdots \mathrm{h})$ do not differed statistically $(\mathrm{P}<0.05)$. 
The presence of essential oils and Citrosept in the medium had an impact on the morphological characteristics of the strain. In the presence of essential forest mycelium it was much lower and more compact than in the controls (Figure 2).

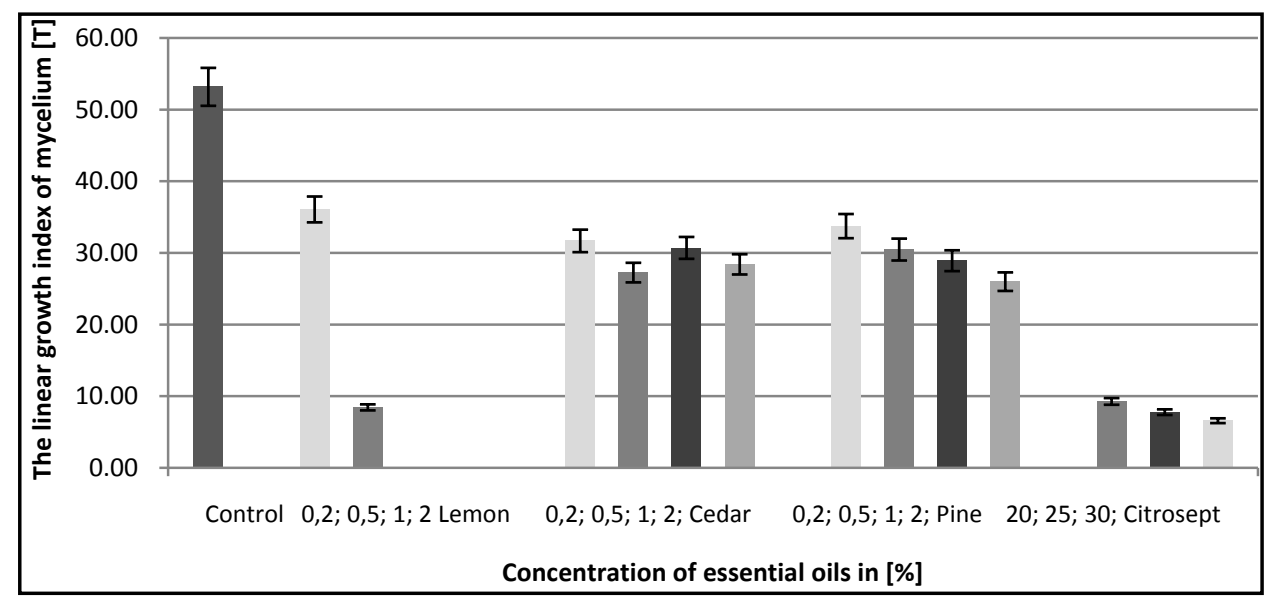

Figure 1. The influence of selected concentrations of essential oils and Citrosept on the growth rate index $(\mathrm{T})$ of mycelium of Fusarium solani with standard deviation $( \pm \mathrm{SD})$.

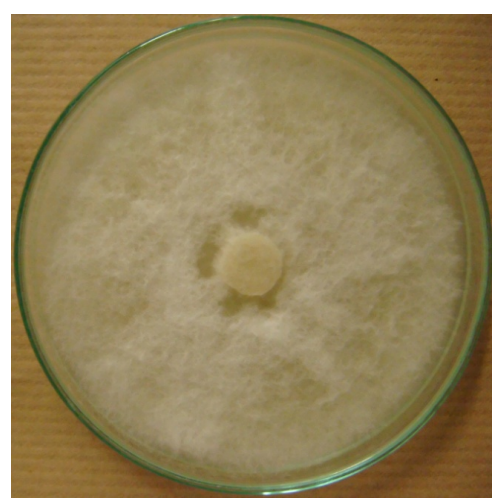

(a)

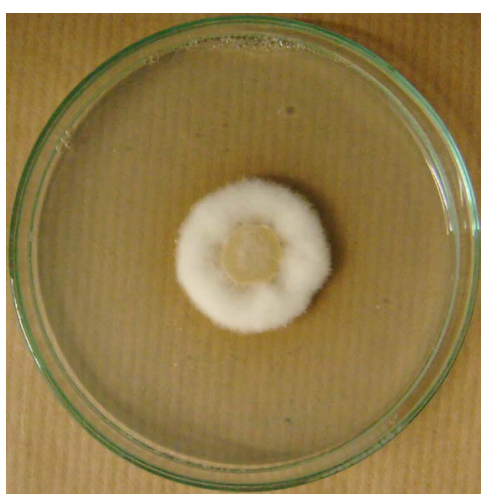

(c)

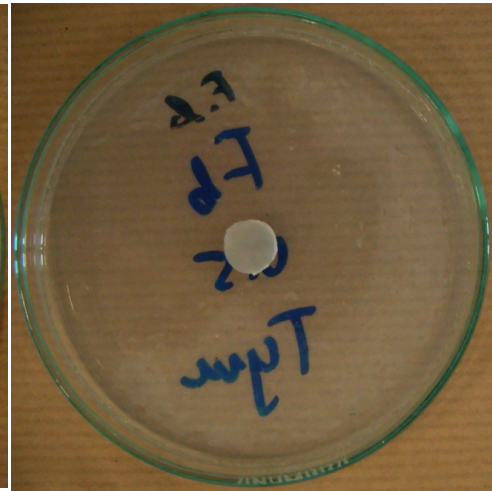

(b)

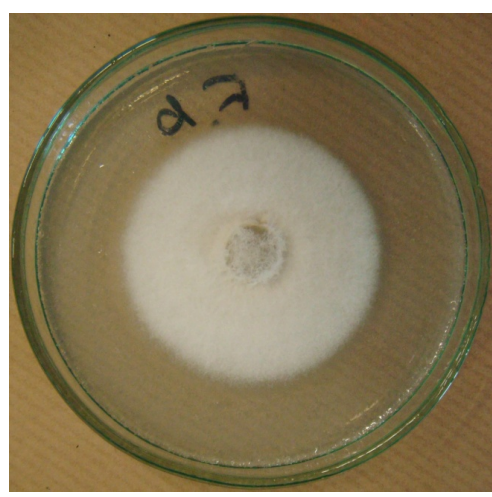

(d)

Figure 2. Fungistatic effects of selected concentrations of essential oils on Fusarium solani after 10 days of incubation in the culture medium; control sample without essential oils (a); $0.2 \%$ thyme oil (b); 30\% Citrosept (c); $2 \%$ pine oil (d). 
Thyme oil was the most effective one in inhibiting the growth of $F$. solani amongst the analysed oils. Thus, further research will concentrate on the possibility of using it as an environment-friendly agent in protection against the dry rot of potato tubers. By applying this oil to food stored in storages one may come closer to completely inhibiting the development of this pathogen on healthy and otherwise undamaged crop.

\section{Conclusions}

1. Thyme oil at a concentration of $0.2 \%-2 \%$ completely inhibited the development of the examined strain of Fusarium solani, which could be used to protect stored potatoes.

2. Citrocept at a concentration of $20 \%-30 \%$ and lemon oil at $1.45 \%$ did slow down mycelium development.

3. No fungistatic properties of cedar and pine oils were detected.

4. The analysed essential oils and Citrosept affected the morphological features of the strain of $F$. solani. The mycelium was significantly smaller in the presence of oils extracted from forest plants and larger when exposed to Citrsept-when compared with the control sample.

\section{References}

[1] Cwalina-Ambroziak, B. and Wróbel, E. (2005) Effect of Nitrogen Fertilization on the Incidence of Major Diseases in Potato Tubers; Newsletter IHAR 237/238, 169-176. (In Polish)

[2] Choroszewski, P. (1993) The Influence of Climatic Conditions on Electric Potato Perpetrators of Diseases in the Years 1979-1988. Bulletin of the Institute of Potato Bonin, 43, 113 129. (In Polish)

[3] Kurzawińska, I. and Gajda, I. (2002) Fungi Colonizing Dry Rotting Potato Tubers; Newsletter IHAR, 223/224, 315-319. (In Polish)

[4] Lenc, L. (2009) Occurrence of Tuber Dry Rot (Fusarium spp.) on Some Potato Cultivars Grown in Organic System. Journal of Research and Applications in Agricultural Engineering, 54, 188-192.

[5] Krzysztofik, B. (2008) The Impact of Storage on Changes in the Quality Characteristics of Potato Tubers. Acta Agrophysica, 11, 449-456. (In Polish)

[6] Czerko, Z. (2002) Storage Technology and the Principles of Construction of Modern Buildings Storage Cabinets. In: Chotkowski, J., Ed., Production and Market of Potatoes in the village of Tomorrow, 234-248. (In Polish)

[7] Viuda-Martos, M., Ruiz-Navajas, Y., Fernandez-Lopez, J. and Perez-Alvarez, J. (2008) Antifungal Activity of Lemon (Citrus lemon L.), Mandarin (Citrus reticulate L.), Grapefruit (Citrus paradise L.) and Orange (Citrus sinensis L.) Essential Oils. Food Control, 12, 1130 1138. https://doi.org/10.1016/j.foodcont.2007.12.003

[8] Sharif, M.A., Atiqur, R., Yunus, A. and Sun, C.K. (2010) Inhibition of Plant Pathogens in Vitro and in Vivo Eith Essential Oil and Organic Extracts of Cestrum nocturnum L. Pesticide Biochemistry and Physiology, 96, 86-92.

[9] Hashem, M., Moharam, A.M. and Zaied, A.A. (2010) Efficacy of Essential Oils in the Control of Cumin Root Rot Disease Caused by Fusarium spp. Crop Protection, 29, 1111-1117. https://doi.org/10.1016/j.cropro.2010.04.020

[10] Shabnam, J., Amna, J., Zaid, M., Arshad, J. and Fouzia, N. (2011) Biocidal Activity of Citrus 
Peel Essential Oils against Some Food Spoilage Bacteria. Journal of Medicinal Plants Research, 5, 3697-3701.

[11] Kirbaşlar, G.F., Tavman, A., Dülger, B. and Türker, G. (2009) Antimicrobial Activity of Turkish Citrus Peel Oils. Pakistan Journal of Botany, 41, 3207-3212.

[12] Sawamura, M., U-Sun, S., Hyang-Sook, C., Lee, K.M., Thi Lan Phi, N., Fears, M. and Kumagai, C. (2004). Compositional Changes in Commercial Lemon Essential Oil for Aromatherapy. International Journal of Aromatherapy, 14, 27-36. https://doi.org/10.1016/j.ijat.2004.02.001

[13] Holley, R.A. and Patel, D. (2005) Improvement in Shelf-Life and Safety of Perishable Foods by Plant Essential Oils and Smoke Antimicrobials. Food Microbiology, 24, 273-292. https://doi.org/10.1016/j.fm.2004.08.006

[14] Barbiel, M. (2012) In Vitro of Didymella bryoniae, Fusarium oxysporum, Trichoderma spp., Sclerotium rolfsii and Thielaviopsis basicola to the Botanical Fungicide Timorex Gold (Melaleuca alternifolia) under the Paper Disk Diffusion and the Poisoning Agar Testing Methods. University of Florida-IFAS, Plant Medicine Program, Gainesville.

[15] Białoń, M., Krzyśko-Łupicka, T., Koszałkowska, M. and Wieczorek, P. (2014) Chemical Composition of Lemon Essential Oils and Their Fungicidal Activity against Candida Yeasts. Mycopathologia, 177, 29-39. https://doi.org/10.1007/s11046-013-9723-3

[16] Jamiołkowska, A. and Wagner, A. (2007) Attempts to Use Thyme Oil to Protect the Peppers Grown in the Field against Pathogenic Fungi. Progress in Plant Protection, 47, 149-153. (In Polish)

[17] Górski, R., Frużyńska-Jóźwiak, D. and Andrzejak, R. (2008) The Impact of Natural Essential Oils on in Vitro Development of the Fungus Trichoderma harzianum Found in Button Mushroom (Agaricus bisporus). Advances of Agricultural Sciences Problem, 529, 19-26. (In Polish)

[18] Settanni, L., Palazzolo, E., Guarrasi, V., Aleo, A., Mammina, C., Moschetti, G. and Germanà, M.A. (2012) Inhibition of Foodborne Pathogen Bacteria by Essential Oils Extracted from Citrus Fruits Cultivated in Sicily. Food Control, 26, 326-330. https://doi.org/10.1016/j.foodcont.2012.01.050

[19] Klimach, A., Wieczorek, W. and Góra, J. (1996) The Influence of Essential Oils in Reducing the Occurrence of Certain Fungal and Bacterial Diseases of Plants. Pesticides, 1, 45-54. (In Polish)

[20] Fisher, K. and Phillips, C. (2008) Potential Antimicrobial Uses of Essential Oils in Food: Is Citrus the Answer? Trends in Food Science \& Technology, 19, 156-164. https://doi.org/10.1016/j.tifs.2007.11.006

[21] Krauze-Baranowska, M., Mardarowicz, M., Wiwart, M., Pobłocka, L. and Dynowska, M. (2002) Antifungal Activity of the Essential Oils from Some Species of the Genus Pinus. Verlag der Zeitschrift für Naturforschung, 57, 478-482. https://doi.org/10.1515/znc-2002-5-613

[22] Kędzia, A., Ziółkowska-Klinkosz, M., Kędzia, A., Wojtaszek-Słomińska, A., Kusiak, A. and Kochańska, B. (2012) Antifungal Activity of Pine Oil (Oleum Pini silvestris). Borgis-Postepy Fitoterapii, 4, 211-215. 
Submit or recommend next manuscript to SCIRP and we will provide best service for you:

Accepting pre-submission inquiries through Email, Facebook, LinkedIn, Twitter, etc. A wide selection of journals (inclusive of 9 subjects, more than 200 journals)

Providing 24-hour high-quality service

User-friendly online submission system

Fair and swift peer-review system

Efficient typesetting and proofreading procedure

Display of the result of downloads and visits, as well as the number of cited articles

Maximum dissemination of your research work

Submit your manuscript at: http://papersubmission.scirp.org/

Or contact aim@scirp.org 